\title{
Determinação de metais tóxicos em sedimento de canal de drenagem pluvial na zona urbana
}

Este estudo foi realizado em um canal de drenagem pluvial da zona urbana da cidade de Pelotas-RS, com o objetivo de determinar os níveis de metais tóxicos $(\mathrm{Cr}, \mathrm{Cu}, \mathrm{Ni}, \mathrm{Pb}$ e $\mathrm{Zn}$ ) no sedimento carreados pelo runoof. Foram coletadas amostra de sedimentos superficiais em cinco pontos ao longo do canal, a fração menor que $63 \mu \mathrm{m}$ sofreu de extração pseudo total nítrico-perclórica e os extratos foram analisados por espectrofotometria de absorção em chama . Os níveis de metais tóxicos encontrados variaram para o Cromo de $2,9 \mathrm{mg} \mathrm{kg}-{ }^{1} \pm 15,4 \%$ à $7,9 \mathrm{mg}$ kg- ${ }^{1} \pm 16,4 \%$, Cobre de $4,7 \mathrm{mg} \mathrm{kg}^{-1} \pm 11,0 \%$ à $20,5 \mathrm{mg} \mathrm{kg-}{ }^{1} \pm 6,2 \%$. O Niquel foi detectado somente no ponto 2 no valor de $2,2 \mathrm{mg}$ kg- ${ }^{1} \pm 2,0 \%$, Chumbo entre $5,4 \mathrm{mg} \mathrm{kg-}{ }^{-1} \pm 2,9 \%$ à $22,6 \mathrm{mg} \mathrm{kg-}{ }^{1} \pm 3,5 \%$ e Zinco $49,0 \mathrm{mg} \mathrm{kg-}{ }^{1} \pm 4,1 \%$ à $100,2 \mathrm{mg} \mathrm{kg-}{ }^{1} \pm 6,8 \%$. De maneira geral os analitos não ultrapassaram os limites estipulados pelo CONAMA 344/2004, não causando danos a biota e vida aquática.

Palavras-chave: Metais Tóxicos; Drenagem Pluvial; Sedimento.

\section{Determination of toxic metals in drainage pluvial channel sediment in urban area}

\begin{abstract}
This study was conducted in a rainwater drainage channel of the urban area of Pelotas, with the aim of determine the concentration of toxic metals ( $\mathrm{Cr}, \mathrm{Cu}, \mathrm{Ni}, \mathrm{Pb}$ and $\mathrm{Zn}$ ) in the sediment carried by runoof. Were collected sample surface sediments at five points along the channel, the fraction less than $63 \mu \mathrm{m}$ was subjected to nitric perchloric acid extraction and the extracts analyzed by flame absorption spectrophotometry. The levels of toxic metals found varied for $\mathrm{Cr} 2.9 \mathrm{mg} \mathrm{kg}{ }^{-1} \pm 15.4 \%$ to $7.9 \mathrm{mg} \mathrm{kg}^{-1} \pm 16.4 \%$, Cu $4.7 \mathrm{mg} \mathrm{kg-}{ }^{-1} \pm 11.0 \%$ to $20.5 \mathrm{mg} \mathrm{kg}^{-1} \pm 6.2 \%$ Ni was detected only in point 2 in the amount of $2.2 \mathrm{mg} \mathrm{kg}^{-1} \pm 2.0 \%$, Pb $5.4 \mathrm{mg} \mathrm{kg}^{-1} \pm 2.9 \%$ to $22.6 \mathrm{mg} \mathrm{kg}{ }^{-1} \pm 3.5 \%$ and $\mathrm{Zn} 49.0 \mathrm{mg} \mathrm{kg}-{ }^{-1} \pm 4.1 \%$ to 100.2 $\mathrm{mg} \mathrm{kg}-{ }^{-1} \pm 6.8 \%$. In general, the analytes did not exceed the limits set by CONAMA 344/2004, causing no damage to biota and aquatic life.
\end{abstract}

Keywords: Toxic Metals; Storm Drainage; Sediment.

\section{Topic: Recursos Hídricos}

Reviewed anonymously in the process of blind peer.

Marcelo Uarthe Grimmler

Instituto Federal de Educação Ciência e Tecnologia Sul Rio Grandense http://lattes.cnpq.br/5722981894689116

marcelogrimmler@hotmail.com

\section{Glauco Rasmussen Betemps}

Instituto Federal de Educação Ciência e Tecnologia Sul Rio Grandense http://lattes.cnpq.br/7450476222967610

glauco.betemps@gmail.com

Mariana Marcant Ferreira

Instituto Federal de Educação Ciência e Tecnologia Sul Rio Grandense http://lattes.cnpq.br/4809008525808454

maryana_mf2@hotmail.com
Received: 25/08/2015

Approved: 24/11/2015

Pedro José Sanches Filho

Instituto Federal de Educação Ciência e Tecnologia Sul Rio Grandense http://lattes.cnpq.br/9785390634457316

pjsans@ibest.com.br

Referencing this:

GRIMMLER, M. U.; BETEMPS, G. R.; FERREIRA, M. M.; SANCHES FILHO, P. J.. Determinação de metais tóxicos em sedimento de canal de drenagem pluvial na zona urbana. Revista Ibero-Americana de Ciências Ambientais, v.7, n.1, p.201-209, 2016. DOI: http://doi.org/10.6008/SPC2179-6858.2016.001.0017 


\section{INTRODUÇÃO}

O crescimento não planejado das cidades tem acarretado, cada vez mais impactos, por ações antrópicas, em ecossistemas, tanto aquáticos como terrestres. Durante o processo de urbanização são projetadas e construídas estruturas para captar águas residuais, esgotos e runoff resultante de precipitações pluviométricas, drenando e conduzindo estas águas a destinos finais como rios e mares. As águas que constituem o runoff escoam pelas superfícies impermeabilizadas urbanas, carregando sólidos suspensos, coloidais e substâncias dissolvidas, constituindo uma mistura heterogênea que inclui compostos orgânicos e inorgânicos como nutrientes, óleos, graxas e metais tóxicos.

Essa carga poluente está associada, principalmente ao trafego de veículos e outras atividades antrópicas, como despejo irregular de esgotos por residências e comércios (GNECO et al, 2005). O runoff urbano é amplamente reconhecido como uma das principais fontes de contaminantes ambientais (BIRCH E TAYLOR, 2002; USEPA, 1983), já que a reunião dessas águas através do sistema de drenagem pluvial juntamente com a carga de poluentes transportadas por estas, pode causar um impacto negativo em diferentes ecossistemas e ambientes aquáticos (BROWN E PEAKE, 2006).

Os metais são considerados contaminantes, devido a sua toxicidade, em alguns casos, carcinogenicidade e mutagenicidade. Estando em contato no ambiente tendem a distribuir-se nos diversos compartimentos ambientais, na água e principalmente nos sedimentos e na biota, (CARMO, et al., 2011).

O sedimento tem grande importância na avaliação da contaminação e poluição dos ecossistemas aquáticos, pois incorpora os poluentes através da adsorção, tornando os menos biodisponíveis (CCME, 2002). Além de acumular os metais, este reservatório pode reprocessar esses materiais oriundos da coluna d'água tornando-os disponíveis novamente ao meio (MARIANI E POMPÊO, 2011). Em canais de baixa vazão, se torna facilitada a precipitação e deposição de sedimentos no fundo, refletindo neste as mesmas características químicas da coluna da água. Sendo o sedimento capaz de acumular diferentes contaminantes, este torna-se um ótimo indicador para monitoramento (ARRIBÉRE et al, 2003).

Os metais tóxicos sendo contaminantes não degradáveis, acumulam-se nos organismos através da bioacumulação e biomagnificação ao longo da cadeia trófica (BAIRD, 2002).

Sendo assim, mesmo depois de cessada a deposição de contaminação por metais tóxicos nesses corpos receptores, a degradação ambiental pode continuar (U.S.EPA 2005).

A cidade de Pelotas situada ao sul do Rio Grande do Sul, com uma população de 328.275 habitantes e uma área de 1.610,084 $\mathrm{Km}^{2}$, está em pleno crescimento urbano (IBGE/2010). A carga de poluentes arrastada pelo runoff urbano é coletada através do sistema de drenagem pluvial, transportada e descarregada principalmente no canal São Gonçalo que por sua vez conecta dois importantes sítios lagunares, Laguna dos Patos e Lagoa Mirim. Desta forma pode refletir o impacto de zonas urbanas sobre este sistema hídrico. 
O objetivo do trabalho é determinar a concentração dos metais traços $\mathrm{Cr}$ (Cromo), $\mathrm{Cu}$ (Cobre), $\mathrm{Ni}$ (Níquel), $\mathrm{Pb}$ (Chumbo) e Zn (Zinco) no sedimento superficial do canal de drenagem pluvial e fazer uma análise da qualidade ambiental desse sistema.

\section{METODOLOGIA}

O canal de drenagem em estudo escoa boa parte das águas pluviais de dois grandes bairros da zona urbana de Pelotas e também é utilizado como receptor de esgoto in natura destes mesmos, pois não dispõe de rede coletora. Nasce no ponto de convergência das avenidas República do Líbano e Salgado Filho, e deságua no Canal São Gonçalo (ROSA, 1985), como mostra a Figura 1.

Localiza se ao longo da Avenida São Francisco de Paula, esta que vem recebendo vários empreendimentos imobiliários de grande porte, como conjuntos residenciais, shopping Center. No entorno dessa Avenida, e em suas proximidades encontra-se uma das regiões em que a cidade está em plena expansão habitacional. Ele recebe ao longo de seu curso o escoamento de estacionamentos, ruas pavimentadas, e da área rural, e também de postos de gasolina. Há também a possibilidade de receber o fluxo ilegal de esgoto doméstico.

Para avaliar as entradas naturais e antropogênicas de metais em um canal de recepção de águas pluviais, cinco amostras de sedimentos foram coletadas em Setembro de 2013 nos locais mostrados na Figura 1.

Amostragem do sedimento do Canal de drenagem pluvial foi realizada em cinco pontos assim distribuídos: Ponto 1 (P1): No entroncamento de duas avenidas pavimentas com fluxo intenso de veículos automotores, próximo a um posto de gasolina; Ponto 2 (P2): Ao lado do shopping Center no escoamento das águas do seu estacionamento no canal; Ponto 3 (P3): Situado nas proximidades de um condomínio residencial em construção, em uma zona menos urbanizada; Ponto 4 (P4): Situado no aporte de um canal afluente que atravessa áreas urbanizadas e com denso tráfego de veículos, junto ao canal em estudo; Ponto 5 (P5): É o encontro do canal com um outro canal de drenagem que atravessa uma área rural com baixa contribuições antropogênicas, situado próximo ao canal São Gonçalo. Os pontos estão apresentados na figura 1.

A posição exata de cada ponto de amostragem (figura 1) foi definida através de medições de GPS (GPS, Global Positioning System, equipamento Garmin \& ETrex ${ }^{\circledR}$, precisão de $\pm 15 \mathrm{~m}$ ).

As amostras dos sedimentos superficiais foram coletadas com uma draga de aço inoxidável do tipo "Van Veen", assim como indica Mozeto (2007). O material coletado foi retirado e armazenado em potes de polietileno, previamente descontaminados. Após coletar todos os pontos, as amostras foram devidamente transportadas e armazenadas em um refrigerador, com temperatura em torno de $4^{\circ} \mathrm{C}$.

A determinação da matéria orgânica no sedimento se deu por calcinação em mufla, a uma temperatura de $550^{\circ} \mathrm{C}$, por um período de 4 horas, objetivando as perdas voláteis da amostra (APHA, 2005). Já na análise granulométrica houve a utilização do método de peneiramento para sedimentos grosseiros, que atende a escala de Wertworth, cuja classificação se dá pelas dimensões dos grãos. Este método foi descrito por Suguio (1973). 

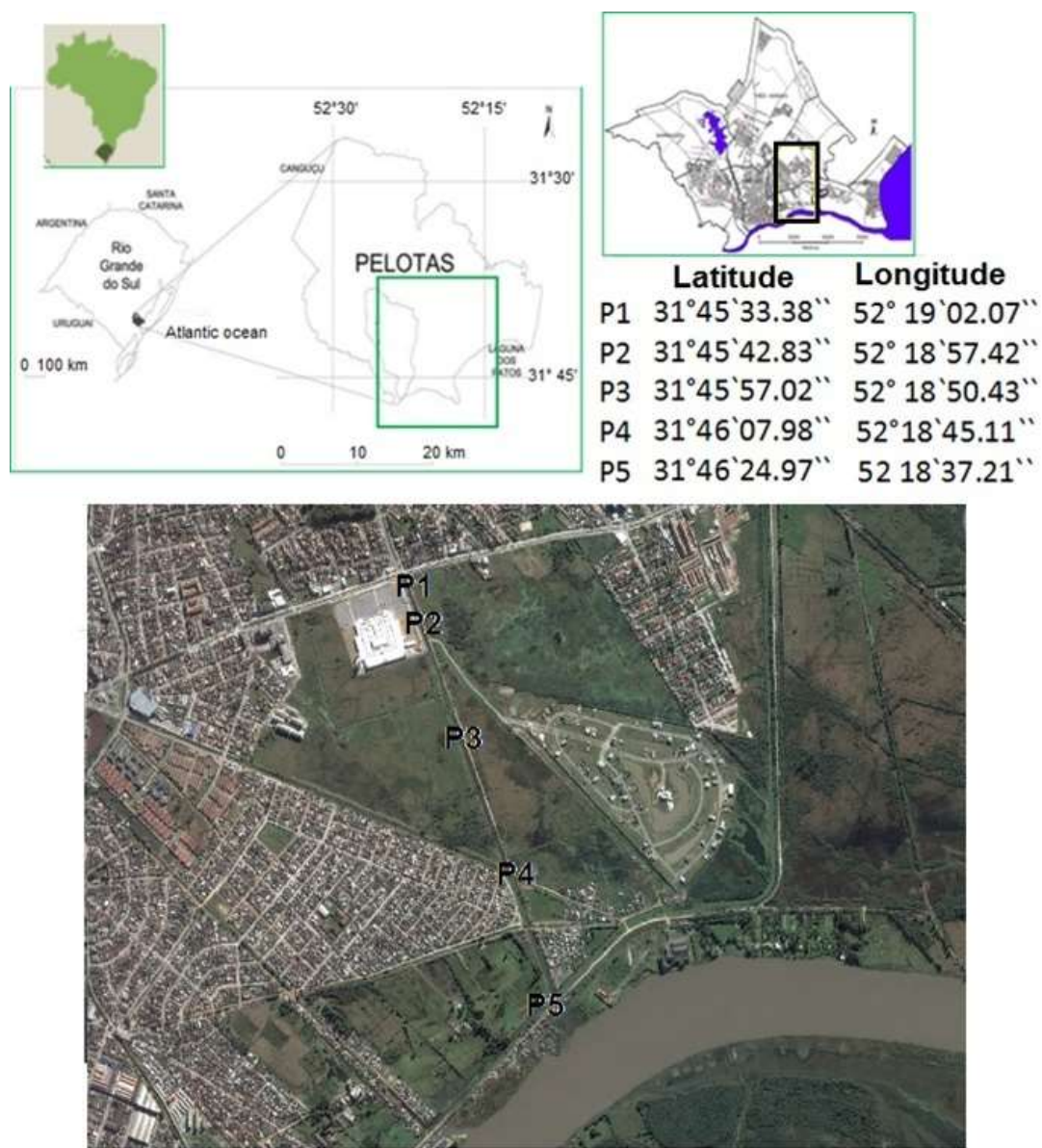

Figura 1: Localização da área de estudo e Georreferências (pontos de coletas e coordenadas).

A umidade foi realizada aquecendo o sedimento em placas de petry na estufa a $105^{\circ} \mathrm{C}$, durante 30 minutos. Conclusa a primeira etapa, foram esfriadas no dessecador e pesadas com cerca de $10 \mathrm{~g}$ de amostra homogeneizada de sedimento. Em seguida, o conjunto foi posto na estufa com temperatura de aproximadamente $105^{\circ} \mathrm{C}$, durante 24 horas. Retiradas da estufa, as amostras foram devidamente resfriadas e pesadas (APHA, 2005).

Para a extração dos metais foi utilizada digestão ácida (Digestão pseudototal), que avalia o grau de metais biodisponíveis no sedimento. As amostras coletadas foram secas em estufa a $60^{\circ} \mathrm{C}$, em um período de 48 horas e logo após maceradas e peneiradas, sendo utilizadas na fração de $<63 \mu \mathrm{m}$. Em tais porções em triplicata foram adicionados $4 \mathrm{~mL}$ de "água régia" (3:1 $\left.\mathrm{HCL}: \mathrm{HNO}_{3}\right), 4 \mathrm{~mL}$ de água destilada e $1 \mathrm{~mL}$ de ácido perclórico $\left(\mathrm{HClO}_{4}\right)$. A solução foi aquecida em "Banho Maria" durante 30 minutos a uma temperatura de $90^{\circ} \mathrm{C}$. (HORTELLANI et al. 2005 - procedimento com adaptações). A solução foi filtrada e transferida para um balão volumétrico de $25 \mathrm{~mL}$, sendo avolumada com água ultra pura.

A certificação analítica foi constituída pela análise de uma amostra de referência IRM-008 para solo e sedimento, obtido da Ultra Scientific Analytical Solutions. Já os limites de detecção (LD) e quantificação (LQ) foram encontrados a partir de dez medidas dos brancos no espectrofotômetro de absorção atômica. Assim, calculando-se o desvio padrão. Para cálculo do limite de detecção foi considerado como sinal analítico mínimo três vezes o desvio padrão dos brancos mais a média do branco, para o LQ procedeu-se da mesma forma, porém utilizando 10 vezes o desvio padrão (IUPAC, 1997: CASTRO et al., 2008). 
A determinação de metais $(\mathrm{Cr}, \mathrm{Cu}, \mathrm{Ni}, \mathrm{Pb}$ e $\mathrm{Zn})$ foi realizada por Espectrofotometria de Absorção Atômica por chama (GBC 932 Plus). Os padrões foram preparados por meio de diluições das soluções padrões marca Titrisol de $1000 \mathrm{mg} / \mathrm{L}$, sofrendo o mesmo tratamento das amostras. As curvas de calibração variaram de 0,2 a $4 \mathrm{mg} \mathrm{L}^{-1}$.

Já as condições operacionais no espectrofotômetro, dos metais analisados, para o Comprimento de Onda e a Energia da Lâmpada para cada elemento, estão apresentadas na tabela 1.

Tabela 1: Comprimento de Onda, Energia da Lâmpada e mistura dos gases utilizados na chama.

\begin{tabular}{cccc}
\hline Elemento & Comprimento de onda $(\mathrm{nm})$ & $\begin{array}{c}\text { Energia da Lâmpada } \\
(\mathrm{mA})\end{array}$ & Chama \\
\hline $\mathrm{Pb}$ & 283,3 & 10,0 & Ar-acetileno \\
$\mathrm{Cu}$ & 324,7 & 15,0 & Ar-acetileno \\
$\mathrm{Zn}$ & 213,9 & 15,0 & Ar-acetileno \\
$\mathrm{Cr}$ & 357,8 & 25,0 & Óxido nitroso-acetileno \\
$\mathrm{Ni}$ & 232,0 & 25,0 & Ar-acetileno \\
\hline
\end{tabular}

nm:nanômetros; mA: miliamper

O material utilizado no tratamento e armazenamento das amostras, como vidrarias em geral, foram descontaminados com uma solução de $\mathrm{HNO}_{3}$ a $10 \%(\mathrm{v} / \mathrm{v})$, por $24 \mathrm{hs}$, com posterior secagem a $105^{\circ} \mathrm{C}$ do material em estufa.

\section{RESULTADOS E DISCUSSÃO}

A tabela 2 apresenta os resultados para os teores de matéria orgânica e umidade em porcentagem. Podemos verificar que os pontos 4 e 2 apresentaram os maiores valores para matéria orgânica e umidade. Estes resultados indicam condições favoráveis para a deposição de contaminantes dentre eles os metais tóxicos. Os altos valores de umidade estão relacionados com água intersticial. Este parâmetro relaciona se de forme direta com alto teor de finos que foi confirmado pelos dados da tabela 3 . Onde os pontos 2 e 4 apresentaram $5,7 \%$ e $9,5 \%$ de finos (silte/argila) respectivamente.

A matéria orgânica e os materiais em suspensão na água tendem a serem carreados para zonas de baixa pressão acumulando-se e dando origem a sedimentos de menor granulometria. Os metais tóxicos que se encontram associados a estes materiais em suspensão farão parte do sedimento resultante (NOALE, 2007).

Tabela 2: Caracterização preliminar do sedimento - Teor de Umidade (\%) e Teor de Matéria Orgânica (\%)

\begin{tabular}{ccc}
\hline Pontos & Umidade (\%) & MO (\%) \\
\hline P1 & $22,3 \pm 0,3$ & $1,8 \pm 14,8$ \\
P2 & $60,4 \pm 10,5$ & $11,1 \pm 6,1$ \\
P3 & $39,7 \pm 4,6$ & $4,8 \pm 22,6$ \\
P4 & $74,4 \pm 0,2$ & $13,7 \pm 2,4$ \\
P5 & $38,6 \pm 17,2$ & $3,7 \pm 17,4$ \\
\hline
\end{tabular}

MO (\%): matéria orgânica em porcentagem.

A tabela 4 e figura 2 apresentam os resultados em $\mathrm{mg} \mathrm{kg}^{-1}$ para os metais determinados neste estudo. Verifica-se que estes foram detectados em quase todos os pontos, apenas $\mathrm{Cr}$ e Ni que não foram detectados nos pontos 1 e 3 . 
Tabela 3: Distribuição Granulométrica em percentual de massa.

\begin{tabular}{|c|c|c|c|c|c|c|c|}
\hline \multicolumn{2}{|c|}{$\begin{array}{c}\text { Grão } \\
\text { (2 mm) }\end{array}$} & $\begin{array}{l}\text { Areia Muito Grossa } \\
(1 \mathrm{~mm})\end{array}$ & $\begin{array}{c}\text { Areia Grossa } \\
(500 \mu \mathrm{m})\end{array}$ & $\begin{array}{c}\text { Areia Média } \\
(250 \mu \mathrm{m})\end{array}$ & $\begin{array}{l}\text { Areia Fina } \\
(125 \mu \mathrm{m})\end{array}$ & $\begin{array}{c}\text { Areia Muito Fina } \\
(63 \mu \mathrm{m})\end{array}$ & $\begin{array}{c}\text { Fundo } \\
(<63 \mu \mathrm{m})\end{array}$ \\
\hline P1 & 27,5 & 35,9 & 29,2 & 5,9 & 1,0 & 0,2 & 0,04 \\
\hline P2 & 11,0 & 20,4 & 22,7 & 18,5 & 13,4 & 8,5 & 5,7 \\
\hline P3 & 24,6 & 22,7 & 19,9 & 14,9 & 10,6 & 4,6 & 2,4 \\
\hline P4 & 7,5 & 20,0 & 20,2 & 15,9 & 16,2 & 10,3 & 9,5 \\
\hline P5 & 9,1 & 16,8 & 21,6 & 16,6 & 21,4 & 9,3 & 4,8 \\
\hline
\end{tabular}

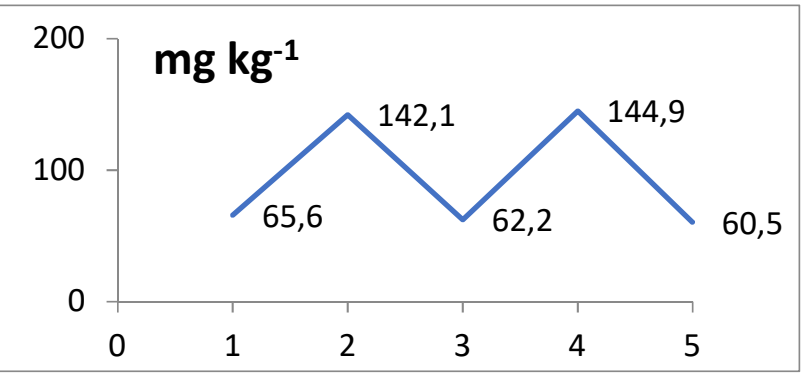

Figura 2: variação do somatório $\left(\mathrm{mg} \mathrm{kg}^{-1}\right)$ dos metais analisado no canal

A figura 2 apresenta o perfil de distribuição do total de metais tóxicos ao longo do canal. Observa-se claramente uma variação na concentração dos metais ao longo do fluxo. Partindo-se de um total de 65,6 mg $\mathrm{kg}^{-1}$ no ponto 1 subindo para $142,1 \mathrm{mg} \mathrm{kg}^{-1}$ no ponto 2 , caindo novamente no ponto 3 para $62,2 \mathrm{mg} \mathrm{kg}^{-1}$, reconcentrando no ponto 4 a $144,9 \mathrm{mg} \mathrm{kg}^{-1}$ e baixando os níveis a $60,5 \mathrm{mg} \mathrm{kg}^{-1}$ no ponto 5 . Observa-se também (tabela 4) o mesmo perfil de concentração dos metais estudados em todos os pontos de amostragem. De forma geral o $\mathrm{Zn}$ apresenta-se como elemento majoritário, seguido pelo $\mathrm{Cu}$ e Pb, resultados que estão em acordo com os estudos desenvolvidos na região por Betemps e Sanches Filho (2012), na Laguna dos Patos, destino final dos contaminantes carreados pelos runoff urbano da região. Os valores estão em acordo com os níveis encontrados em outros canais de drenagem da cidade de Pelotas avaliados por outros autores conforme tabela 5 .

A predominância do Zinco vem sendo justificada em função da geologia da região (SILVA, 2009) e também por ser um elemento amplamente utilizado pelo homem. O zinco e seus compostos têm muitos usos na indústria automobilística, de construção civil e de eletrodomésticos. É usado na fabricação de ligas resistentes à corrosão e na galvanização de produtos de ferro e aço. Os principais compostos de zinco são os óxidos ( $\mathrm{ZnO})$, utilizados nas indústrias de cerâmica, borracha e tintas; o sulfato de zinco (ZnSO4) com aplicação na indústria têxtil e no enriquecimento de solos pobres em zinco; e o cloreto de zinco usado para preservar madeiras e em pilhas secas e tintas. Outros compostos são empregados na indústria farmacêutica para fabricação de bloqueadores solares, desodorantes, preparações para tratamento de micoses, acne e xampu anti-caspa (CETESB 2012).

Constata-se também a estreita relação entre o total de metais tóxicos (¿Metais) determinado em cada ponto com os níveis de MO e finos o que é confirmado pelos elevados valores dos coeficientes de correlação de Pearson entre $\sum$ Metais x MO de 0,96 e $\sum$ Metais X finos de 0,78.

$\mathrm{O}$ ponto 1 apresentou menores níveis de concentração, sendo quantificados apenas $\mathrm{Cu}, \mathrm{Pb}$ e $\mathrm{Zn}$, este ponto apresenta um desnível em seu leito, criando uma área de alta turbulência. Tal situação pode varrer os grãos finos e a matéria orgânica para o ponto 2 , resultando um sedimento de granulometria maior 
com menor capacidade de adsorção de metais, o que já havia sido verificado pelas caracterizações preliminares apresentadas nas tabelas 2 e 3.

Todos os analitos foram quantificados no ponto 2 , este junto com o ponto 4 apresentaram os maiores níveis de contaminantes. Os níveis de metais tóxicos no ponto 2 podem estar relacionados com a proximidade deste com as avenidas pavimentas com fluxo intenso de veículos automotores que se cruzam neste ponto, com o estacionamento do Shopping Center e com as condições hidrodinâmicas que provocam a deposição de metais nesse ponto, mesmo com altos valores de metais tóxicos em relação aos demais pontos, nenhum dos analitos atingiu concentrações superiores ao TEL (Threshold Effect Level): valor abaixo do qual raramente ocorre efeitos biológicos (Água doce), e ao PEL (Probable Effect Level): Valor acima do qual efeito adverso é esperado (Água doce), não representando risco a vida aquática. Estes níveis estão descritos na CCME - Canadian Environmental Quality Guidelines - 2002, e são os mesmos utilizados pelo CONAMA. Os valores indicados para TEL e PEL correspondem aos valores do nível 1 e nível 2 estabelecidos na resolução CONAMA 344/2004, para a qualidade dos sedimentos de água doce.

O ponto 3 representa uma região intermediária entre o ponto 2 e o ponto 4, esta área não recebe nenhum afluente que possa contribuir com o aumento dos contaminantes, os valores encontrados neste ponto indicam uma diluição na concentração dos metais. Os baixos teores de M.O. e alta granulometria sugerem condições que não favorecem a deposição.

No ponto 4 além das condições adequadas de M.O e teor de finos, encontra-se a fusão com outro importante canal de drenagem que recebe esgoto e runoff de outra área da cidade, colaborando com aporte de sedimento transportados por este. Os valores máximos e mínimos transportados por este afluente foram descritos por Medran e Sanches Filho (2013) e estão representados na tabela 5 e corroboram para a influência do mesmo, para este tipo de impacto. Os resultados encontrados neste ponto estão acima dos descritos por Medran e Sanches Filho (2013), o que sugere um acúmulo em relação ao somatório das cargas de contaminantes neste entroncamento.

No ponto 5 os resultados quantificados, diminuem seu valor em relação ao ponto 4, é possível que isso ocorra pelas condições físico-químicas que voltam a não estar ideais para deposição e adsorção dos metais no sedimento e também pelo aporte de um outro afluente advindo de um canal de drenagem que atravessa uma zona rural da cidade com menor carga de contaminantes, podendo assim diluir os contaminantes oriundos do ponto 4 .

Tabela 4: Níveis dos metais analisados no canal de drenagem, com seus respectivos desvios padrões relativos (\%), seguidos dos limites de detecção (LD) e limite de quantificação (LQ).

\begin{tabular}{|c|c|c|c|c|c|}
\hline \multirow[t]{2}{*}{ Pontos } & \multicolumn{5}{|c|}{$\mathrm{mg} \mathrm{kg}^{-1} \pm \% \mathrm{RSD}$} \\
\hline & $\mathrm{Cr}$ & $\mathrm{Zn}$ & $\mathrm{Cu}$ & $\mathrm{Pb}$ & $\mathrm{Ni}$ \\
\hline 1 & $\mathrm{Nd}$ & $55,5 \pm 8,9$ & $4,7 \pm 11,0$ & $5,4 \pm 2,9$ & $\mathrm{Nd}$ \\
\hline 2 & $2,9 \pm 15,4$ & $93,9 \pm 2,1$ & $20,5 \pm 6,2$ & $22,6 \pm 3,5$ & $2,2 \pm 2,0$ \\
\hline 3 & $\mathrm{Nd}$ & $46,3 \pm 4,2$ & $9,2 \pm 16,6$ & $6,7 \pm 4,8$ & $\mathrm{Nd}$ \\
\hline 4 & $7,9 \pm 16,4$ & $100,2 \pm 6,8$ & $19,6 \pm 13,3$ & $17,2 \pm 7,9$ & $<\mathrm{LQ}$ \\
\hline 5 & $\mathrm{Nd}$ & $49,0 \pm 4,1$ & $5,5 \pm 7,8$ & $6,0 \pm 6,5$ & $\mathrm{Nd}$ \\
\hline $\operatorname{LD}^{(1)}$ & 2,18 & 1,44 & 0,65 & 0,53 & 0,3 \\
\hline $\mathrm{LQ}^{(2)}$ & 2,78 & 5,4 & 3,35 & 0,81 & 2,0 \\
\hline
\end{tabular}




$\begin{array}{lccccc}\text { TEL (3) } & 37,3 & 123 & 35,7 & 35 & 18 \\ \text { PEL }{ }^{(4)} & 90 & 315 & 197 & 91,3 & 35,9\end{array}$

LD: Limite de Detecção; LQ: Limite de Quantificação; TEL: Threshold Effect Level. Valor abaixo do qual raramente ocorre efeitos biológicos (Água doce); PEL: Probable Effect Level. Valor acima do qual efeito adverso é esperado (Água doce); $\mathrm{Nd}$ : não determinado.

Tabela 5: Níveis de metais tóxicos determinados na região de Pelotas-RS

\begin{tabular}{|c|c|c|c|c|c|c|}
\hline \multirow{2}{*}{ Recurso Hídrico } & \multicolumn{4}{|c|}{ Concentração (mg kg-1 \pm RSD\%) } & \multirow[b]{2}{*}{$\mathbf{N i}$} & \multirow{2}{*}{ Referência } \\
\hline & $\mathrm{Cr}$ & $\mathrm{Cu}$ & $\mathrm{Pb}$ & $\mathrm{Zn}$ & & \\
\hline Sta Bárbara & $\begin{array}{l}2,5 \pm 1,4- \\
21,4 \pm 4,6\end{array}$ & $\begin{array}{c}3,3 \pm 2,5 \\
42,6 \pm 9,8\end{array}$ & $\begin{array}{l}4,7 \pm 23,5 \\
16,2 \pm 0,2\end{array}$ & $\begin{array}{l}5,2 \pm 18,2 \\
40,4 \pm 2,1\end{array}$ & $\mathrm{Nd}$ & Sanches Filho (2012) \\
\hline Pontal da Barra & $\mathrm{Nd}$ & $\begin{array}{c}4,4 \pm 5,7 \\
13,2 \pm 1,0\end{array}$ & $\begin{array}{c}12,7 \pm 2,3 \\
23,21 \pm 6,4\end{array}$ & $\begin{array}{l}20,3 \pm 7,3 \\
37,7 \pm 1,1\end{array}$ & $\mathrm{Nd}$ & $\begin{array}{l}\text { Caldas \& Sanches Filho } \\
\text { (2010) }\end{array}$ \\
\hline $\begin{array}{l}\text { Canal Av. Bento } \\
\text { Gonçalves }\end{array}$ & $\begin{array}{c}8,2 \pm 1,1 \\
10,9 \pm 1,04\end{array}$ & $\begin{array}{c}0.6 \pm 0,03 \\
38,4 \pm 2,18\end{array}$ & $\begin{array}{l}14,2 \pm 0,36 \\
33,4 \pm 4,19\end{array}$ & $\begin{array}{l}10,1 \pm 0,67 \\
82,6 \pm 1,0\end{array}$ & $\begin{array}{l}2,9 \pm 0,40 \\
6,7 \pm 0,42\end{array}$ & $\begin{array}{c}\text { Medran \& Sanches Filho } \\
\text { (2013) }\end{array}$ \\
\hline Presente estudo & $\begin{array}{l}2,9 \pm 15,4 \\
7,9 \pm 16,4\end{array}$ & $\begin{array}{r}4,7 \pm 11,0 \\
20,5 \pm 6,2 \\
\end{array}$ & $\begin{array}{r}5,4 \pm 2,9 \\
22,6 \pm 3,5\end{array}$ & $\begin{array}{c}49,0 \pm 4,1 \\
100,2 \pm 6,8 \\
\end{array}$ & $\begin{array}{c}N d \\
2,2 \pm 2,0\end{array}$ & Presente estudo \\
\hline
\end{tabular}

Nd: Não detectado

Os valores apresentados na Tabela 6 demonstram que as recuperações para o material certificado se apresentaram acima de 90\%, com exceção do cromo. Segundo Jesus (2004), é considerado aceitável, recuperações entre 75 e 110\%. O cromo normalmente não está dentro desta faixa de recuperação, porque o material não sofre uma digestão total, podendo estar intimamente ligado a silicatos que são difíceis de serem solubilizados. (HORTELLANI, 2005). Desse modo, os resultados demonstram que o método de extração foi adequado ao experimento.

Tabela 6: Níveis certificados e intervalo de confiabilidade do material certificado IRM-008 adquirido da Ultra Scientific, teor encontrado, ambos em $\left(\mathrm{mg} \mathrm{Kg}^{-1}\right)$ e seus respectivos desvios padrões e o percentual de recuperação para cada metal.

\begin{tabular}{cccccc}
\hline Analito & $\mathbf{N i}$ & $\mathbf{C r}$ & $\mathbf{C u}$ & $\mathbf{P b}$ & $\mathbf{Z n}$ \\
\hline Valor certificado & 26,0 & 48,1 & 36,4 & 95,3 & 133,5 \\
Intervalo de confiabilidade & $23,8-28,1$ & $43,40-52,80$ & $34,80-37,90$ & $90,00-101,0$ & $126,0-141,0$ \\
Valor encontrado & $24,3 \pm 0,1$ & $28,30 \pm 0,02$ & $35,67 \pm 0,36$ & $94,25 \pm 1,34$ & $127,56 \pm 0,56$ \\
Recuperação (\%) & 93,4 & 58,80 & 97,90 & 98,80 & 95,55 \\
\hline
\end{tabular}

\section{CONCLUSÃO}

Através dos resultados obtidos neste estudo para o canal de drenagem pluvial da Avenida São Francisco de Paula com foco nos metais tóxicos $\mathrm{Cr}, \mathrm{Cu}, \mathrm{Ni}, \mathrm{Pb}$ e $\mathrm{Zn}$, pode-se confirmar a presença destes analitos ao longo de seu curso. Embora detectados e quantificados os níveis de contaminação, não ultrapassaram os limites estabelecidos para o TEL e PEL, o que indica o baixo impacto por metais tóxicos neste ambiente. Cabe ressaltar que estes analitos são bioacumulativos e mesmo em baixas concentrações podem ao longo do tempo vir a causar dano a saúde ambiental. Outro ponto importante que devemos destacar que esses resultados são produto de apenas uma coleta, onde ficou evidenciado o transporte destes contaminantes gerados na zona urbana para zonas de extrema importância econômica, turística e ambiental. Estes dados devem ser considerados para que os órgãos competentes, possam acompanhar a evolução dos níveis de metais tóxicos e projetar medidas de saneamento para o controle desse impacto que futuramente pode ocasionar danos irreversíveis a população. 


\section{REFERÊNCIAS}

APHA, Standard Methods for the Examination of Wather and Wastewater. 21 ed. 2005.

BAIRD, C.. Química ambiental. 2 ed. Bookman, 2002.

BETEMPS, G. R.; SANCHES FILHO, P. J.. Estudo sazonal de metais tóxicos no sedimento do saco do Laranjal - Pelotas RS. Jounal Brazilian Socety Ecotoxicology, V.7, p.79- 84, 2012. DOI: http://doi.org/10.5132/jbse.2012.02.012

BIRCH, G. F.; TAYLOR, S. E.. Assessment of possible sediment toxicity of contaminated sediments in Port Jackson, Sydney, Australia. Hydrobiologia, 2002.

BROWN, J. N.; PEAKE, B. M.. Sources of heavy metals and polycyclic aromatic hydrocarbons in urban stormwater runoff. Science of the Total Environment, 2006. DOI: http://doi.org/10.1016/j.esitotenv.2005.05.016

CALDAS, J. S.; SANCHES FILHO, P. J.. Determinação de Cu, Pb e Zn no sedimento da região do Pontal da Barra, Laranjal (Laguna dos Patos, Pelotas - Brasil). Brazilian Jounal Aquatic Science Technology, v.17, n.1, p.13-18, 2013.

CARMO, C. A.; ABESSA, D. M. S.; MACHADO NETO, J. G.. Metais em águas, sedimentos e peixes coletados no Estuário de São Vicente SP, Brasil. O Mundo da Saúde, v.35, n.1, p.64-70, 2011.

CCME. Canadian Environmental Quality Guidelines. 2002.

CONAMA. Conselho Nacional do Meio Ambiente. Resolução $\mathbf{n}^{0}$ 344, de 25 de março de 2004. Estabelece as diretrizes gerais e os procedimentos mínimos para a avaliação do material a ser dragado em águas jurisdicionais brasileiras e dá outras providências. DOU, 2004.

DAVIS, B. S.; BIRCH, G. F.. Catchment-wide assessment of the cost-effectiveness of storm water remediation measures in urban areas. Environmental Science \& Policy, 2009. DOI: http://doi.org/10.1016/j.envsci.2008.09.004

GNECCO, T.; BERRETTA, C.; LANZA, L. G.; LA BARBERA, P.. Storm water pollution in the urban environment of Genoa, Italy, Atmospheric Research, v.77, p.60-73, 2005. DOI: http://doi.org/10.1016/j.atmosres.2004.10.017

HORTELLANI, M. A.; SARKIS, J. E. S.; ABESSA, D. M. S; SOUZA E. C. M. 2005. Avaliação de contaminação por elementos metálicos dos sedimentos de Estuário de Santos - São Vicente. Química Nova. 31 (1): 1-10.

IBGE. Instituto Brasileiro de Geografia e Estatística. 2010.
IUPAC. International Union of Pure and Applied Chemistry. Chemistry compendium of chemical terminology. 2 ed. Oxford: Blackwell Scientific Publications, 1997.

JESUS, H. C.; COSTA, E. A.; MENDONÇA, A. S. F.; ZANDONADE, E.. Distribuição de metais tóxicos em sedimentos do sistema estuarino da llha De Vitória - ES. Química Nova, v.27, n. 3, p.378-386, 2004.

ARRIBÉRE, M. A.; GUEVARA, S. R.; SÁNCHES, R. S.; GIL, M.I.; ROSS, G. R.; DAURADE, L. E.; FAJON, V.; HORVAT, M.; ALCADE, R.; KESTELMAN, A. J... Heavy metals in the vicinity of a factory in the upper Negro River ecosystem, Northern Patagonia, Argentina. Science of the total Environ, 2003.

MARIANI, C. F.; POMÊO, M.. Sedimento: como avaliar sua contaminação por metais. Saneas, v.12, n.40, p.10-13, 2011.

MOZETO, A. A.. Sedimentos e particulados lacustres: amostragens e análises biogeoquímicas. 2007.

NOALE, R. Z.. Avaliação do risco ambiental em sedimentos dos lagos do riacho Cambé em Londrina pela distribuição de metais. Dissertação (Mestrado) - Universidade de Londrina. 2007.

ROSA, M.. Geografia de Pelotas. EdUFPel. 1985.

SANCHES FILHO, P. J.; BETEMPS, G. R.; MESENBURG, A. P.; ALFONSO, P.. Determination of trace metals in sediment samples of the Santa Bárbara Channel/Pelotas/RS/BRAZIL. Jounal of Environmental Chemistry and Ecotoxicology, v.5, n.7, p.190-195, 2013. DOI: http://doi.org/10.5897/GECE 2013.0281

SILVA, J. B.. Micronutrientes em perfis de solos do Estudo Sul-rio-grandense. Dissertação (Mestrado em Agronomia) Universidade Federal de Pelotas, 2009.

SUGUIO, K.. Introdução à sedimentologia. São Paulo: EDUSP, 1973.

U.S.EPA. United States Evironmental Proteticon Agency. Procedure for the derivation of Equilibriun Partitioning Benchmarks (ESBs) for the protection of benthic organisms: metal mixtures (cadmium, Cooper, lead, nickel, silver and zinc. Washington: Office of Research and Development (EPA600-R-02-011), 2005.

YOON, J.; CAO, X.; ZHOU, Q.; MA, L. Q.. Accumulation of Pb, $\mathrm{Cu}$, and $\mathrm{Zn}$ in native plants growing on a contaminated Florida site. Science of the Total Environment, n.368, p.456464, 2006. DOI: http://doi.org/10.16/J.SIOTENV.2006.01.016 